\title{
A RESSIGNIFICAC̣ÃO DAS ATIVIDADES NA SALA DE AULA
}

Jesuína L. A. Pacca*

Anne L. Scarinci**

RESUMO: Neste texto investigam-se concepções de professores sobre três estratégias de ensino - aula expositiva, aula experimental e aula de demonstração - e analisa-se o seu processo de ressignificação, dirigido à coerência com princípios construtivistas de ensino e aprendizagem que os professores protagonizam em um programa de formação contínua. Para que a ressignificação de uma atividade pudesse ocorrer, os professores experienciaram fases de estranhamento, operacionalização e conscientização e tiveram oportunidade, nesse percurso, de aprofundar conhecimentos sobre o construtivismo no que se refere à sua tradução para situações de sala de aula. Partindo de concepções ingênuas, perceberam que não é o tipo de atividade que determina um ensino construtivista, mas a maneira como esta é entendida e considerada na sala de aula e na sequência didática.

Palavras-chave: Ressignificação de Atividades Didáticas; Construtivismo na Sala de Aula; Formação de Professores.

\section{THE RE-MEANING OF CLASSROOM ACTIVITIES}

ABSTRACT: Teachers' conceptions about three teaching strategies - lectures, experimental classes and demonstrations - are investigated, as well as their process of re-meaning, heading coherence with constructivist principles of teaching and learning, that teachers accomplish in a professional development program. For the re-meaning to occur, teachers experienced phases of awkwardness, operationalization and consciousness and had the opportunity, on the way, to deepen knowledge on constructivism with respect to its translation to classroom instances. Departing from naive conceptions, they realized it is not the type of activity what determines a constructivist teaching, but the way it is approached and considered in the classroom and in the didactic sequence.

Keywords: Re-Meaning of Didactic Activities; Constructivism in the Classroom; Teachers' Formation.
*Doutora em Educação pela
Universidade de São Paulo
(USP). Professora Associada
no Instituto de Física da
Universidade de São Paulo
(USP).
E-mail:
jepacca@if.usp.br
* Doutora em Ensino de
Ciências (Modalidade Física)
pela Universidade de São
Paulo (USP).
E-mail:
I.scarinci@gmail.com 


\section{INTRODUÇÃO}

Nos últimos 20 anos, adotar o construtivismo se constituiu desejo de todo professor preocupado com o sucesso das suas aulas. Ao mesmo tempo, muitos pesquisadores em ensino de Ciências trabalharam exaustivamente para compreender o que significava e como se caracterizava essa atuação, bem como para produzir subsídios para a implementação de procedimentos construtivistas na sala de aula, com alunos reais.

A ideia de estar praticando um ensino transmissivo tornou-se terrível e desagradável para os professores e muitos se esforçam para fugir disso, adotando alguns procedimentos que procurassem, de algum modo, envolver os aprendizes e mantê-los ocupados com tarefas interessantes.

A conscientização de que os aprendizes pensam e têm modelos alternativos para explicar os fatos científicos foi o grande propulsor dos trabalhos de pesquisa e de propostas de programas de ensino, especialmente na década de 80. A década seguinte se caracterizaria pela atenção ao professor e à sua formação, principalmente à formação em serviço. $\mathrm{O}$ objetivo seria atualizar os professores com as descobertas sobre conhecimentos prévios dos alunos acerca dos conteúdos científicos e com propostas de novos modos de trabalhar na sala de aula, possíveis de serem implementadas. Entretanto, a implementação não ocorreu como desejada.

Por que os professores não dão as respostas que os pesquisadores pedem e esperam e, ao mesmo tempo, mostram competência para assumir a sala de aula mesmo em condições adversas, revelando intuição e sensibilidade para compreender que algo não está bem dentro da rotina que conseguem manter? E alguns chegam a se surpreender com os resultados da sua tarefa. Uma professora, participante de um programa de formação que coordenamos, se expressou significativamente nesse sentido: "Os alunos aprendem mais do que a gente ensinou".

Paralelamente a essas questões amplamente veiculadas e extremamente atraentes para quem se interessa pela Educação em geral ou Científica em particular, a preocupação com a incorporação dos resultados das pesquisas na sala de aula e nos currículos das licenciaturas foi e continua sendo tema constante nas reuniões científicas que tratam de pesquisar a aprendizagem das Ciências. Por que o professor não consegue levar para suas aulas o resultado das pesquisas que parecem tão relevantes, pertinentes e esclarecedoras de problemas do cotidiano docente? Por que o professor não consegue ser construtivista nas suas aulas? Talvez porque as ideias construtivistas como concebidas pelos seus autores não se apresentam de forma pragmática ou como normas para serem aplicadas para a sala de aula (LAJONQUIĖRE, 1992).

Depois de participar ativamente de um curso de aperfeiçoamento que se baseava nas concepções espontâneas dos alunos, obtidas através da análise de questionários a eles aplicados, uma professora se expressava assim: "Já sei como identificar as concepções espontâneas nas respostas dos meus alunos, mas não sei o que faz̧er com elas." 
$\mathrm{Na}$ tentativa de compreender tais dificuldades, buscamos na literatura teorias e concepções sobre a construção do conhecimento científico pelo sujeito que aprende e sobre o ensino que favorece a aprendizagem significativa e duradoura. As concepções de Jean Piaget e de Paulo Freire sobre conhecer e aprender trouxeram alguma luz a essas questões de modo geral e é nesses autores que buscamos a concepção de construtivismo, sem querer dizer que eles se apresentaram como tal e prescreveram métodos ou receitas do que seria uma aula com base nas suas concepções. Interessa-nos Piaget (1977), tratando do processo dialético que leva à construção do conhecimento científico a partir da interação constante do sujeito com a realidade e da tomada de consciência sobre esse conhecimento; interessa-nos Paulo Freire (1996), tratando desse processo ligado fortemente ao conhecimento conceituado socialmente, num movimento contínuo de significação e ressignificação de conteúdos.

\section{AS ESTRATÉGIAS CONSTRUTIVISTAS NAS ATIVIDADES DA SALA DE AULA}

Incorporando as tendências construtivistas da pesquisa em ensino de Ciências e principalmente a adoção de teorias de aprendizagem consideradas construtivistas no final do século XX, a Escola foi obrigada a ser construtivista. Os currículos adotaram termos e formas entendidas como tal e a equipe docente deveria seguir determinadas orientações para dar aulas dentro da nova concepção.

Os professores foram informados de que para serem construtivistas não deviam dar respostas às perguntas dos alunos e, se possível, deviam fazer (outras) perguntas; deviam fazer experiências na aula, de preferência dando acesso direto à manipulação dos alunos; deviam respeitar o nível e ritmo dos alunos; deviam evitar discursos do professor ( $\not$.e. aulas expositivas) e deixar que os alunos se expressassem; deviam estimular atividades extra-classe (projetos e feiras); deviam sugerir pesquisas; ... E foi assim que, via de regra, o professor procurou transformar suas aulas em construtivistas.

$\mathrm{Na}$ maioria das vezes, as transformações que ele produzia eram apenas periféricas, isto é, ao nível das atividades de ensino constantes dos planos de aula do professor. O cerne - as concepções sobre formas de interação que conduzem ao aprendizado - permanecia intacto.

De fato, em pouco tempo, ele estaria voltando ao que fazia antes, porque parece que dava melhor resultado, com maior segurança para o seu desempenho e com a garantia de cumprir um programa que os alunos e a escola esperavam dele. Mas a frustração ficava, especialmente para um profissional consciente do seu papel de educador; o profissional que percebia uma falta de sintonia nas relações pedagógicas e se surpreendia com o saber dos seus alunos.

Além do teor informativo daquilo que os cursos de formação conseguem geralmente transferir, é muito pouco o que se transforma numa mudança 
significativa na concepção do professor e na possibilidade de aplicação no seu trabalho. De outro lado, a intuição que o professor manifesta para dar sequência às suas aulas e cumprir um programa parece ser desprezada pelos cursos, ignorando que o professor também pensa e que de alguma maneira sabe dar as suas aulas. O professor, de fato, possui uma competência e um conjunto de saberes complementares aos veiculados pelos programas de formação que poderiam ser aproveitados e conectados com os novos conhecimentos que os programas oferecem.

A questão da baixa eficiência dos cursos de formação é uma questão que preocupa os pesquisadores ainda hoje (FUSARI, 1998). E parece que nem mesmo os cursos de formação inicial e contínua, utilizando procedimentos e atividades coerentes com a concepção construtivista de ensinar e aprender, têm encontrado muito sucesso nessa tarefa. O que está faltando? Confrontar o professor com a situação real do ensino que ele produz e dos resultados de aprendizagem que ele é capaz de encontrar pode ser um caminho, e indícios disto estão contidos na análise que realizamos com o grupo de professores sujeitos deste trabalho.

\section{CONTEXTO DA PESQUISA}

O grupo estudado participa de um projeto de formação contínua apoiado pela Fundação de Amparo à Pesquisa do Estado de São Paulo FAPESP -, cujo objetivo fundamental é ajudar o professor a planejar suas aulas a partir de ideias coerentes com concepções de ensino e aprendizagem de cunho construtivista. O projeto conta com a coordenadora e três colaboradores (pesquisadores de Doutorado). São participantes nove professoras de Física do Ensino Médio. As estratégias utilizadas no programa de formação baseiam-se essencialmente no desenvolvimento dos planejamentos pessoais e no acompanhamento das professoras a partir dos relatos que elas fazem de suas aulas, após aplicarem o planejamento que é, assim, continuamente reelaborado.

O que se procura na ação e na interação com as professoras é partir daquilo que elas sabem fazer e levá-las a reformular esse saber, com objetivos que apontam para a inclusão efetiva do aluno no processo de aprender, enfatizando a manutenção de um diálogo significativo (para professor e aluno) na sala de aula. Sendo assim, as atividades que elas planejam e aplicam na sala de aula segundo o planejamento pedagógico - são escolhidas e definidas por elas mesmas. Suas propostas, incluindo o resultado do trabalho com seus alunos, são relatadas nos encontros e o trabalho do formador é dirigir a discussão dentro do grupo, tendo sempre referência nos objetivos do programa (VILLANI \& PACCA, 1992; ibid, 1996).

Algumas atividades mais comuns e presentes no dia-a-dia da sala de aula foram também utilizadas dentro do programa de formação, onde o profes- 
sor ocupa a posição de aluno. Neste planejamento do programa, os momentos da inclusão de diferentes atividades foram escolhidos de modo a tornar a atividade significativa para os professores-aprendizes e resultar na aprendizagem específica da ação de ensinar o conteúdo da sua matéria. Suas reações, expressões e comentários ao longo do programa foram registrados em gravações; esse material foi complementado por registros escritos sobre seus trabalhos pedagógicos e posteriormente o material foi analisado.

As professoras tiveram participação ativa e intensa de acordo com suas personalidades, caracterização que consideramos propícia para o desenvolvimento de um programa com esses moldes. Embora tenham se comportado, especialmente no início do programa, mais como alunas do que como professoras, aos poucos, foram se integrando na proposta de produzir um planejamento capaz de ensinar e motivar/mobilizar os alunos para aprender, aceitando críticas do formador e de todos os participantes do grupo.

As atividades utilizadas durante boa parte do tempo do programa consistiam principalmente de discussões, orientadas pela coordenadora, sobre questões de diversas naturezas (elaboração de planejamentos, condução das aulas, conteúdos de Física, posicionamentos político-pedagógicos, etc.), realização de experiências programadas, resolução de questões conceituais essenciais dentro do conteúdo, registros escritos sobre dúvidas e sobre resultados atingidos, bem como considerações num campo educacional mais amplo, extrapolando a sala de aula. Essas atividades e seus conteúdos eram definidos pela coordenadora (na função de formadora) ao longo do programa de formação, atendendo às necessidades trazidas pelas professoras.

A preocupação em manter o diálogo com e dentro do grupo foi uma constante no trabalho de formação. A partir de certo momento, após cerca de seis meses do transcurso do programa, foram introduzidas atividades com maior exigência quanto à participação individual do professor: seminário, apresentação de algum material gerado nas suas aulas e também a apresentação de uma aula expositiva que desse conta do conteúdo desenvolvido com os alunos até aquela data.

Evidentemente, esperávamos que as atividades e procedimentos/comportamentos adotados pela equipe formadora (que inclui a coordenadora e os três pesquisadores em Ensino de Ciências) pudessem, em alguma medida, ser levados para a sala de aula; esse resultado já havia sido encontrado e relatado em pesquisas anteriores (PACCA \& VILLANI, 2000). Muitas dessas atividades e tarefas foram implementadas com seus alunos, especialmente as experiências que eram realizadas e esmiuçadas para a compreensão desejada do conteúdo mas, apesar de serem atividades já experimentadas por elas, também ocorreram dificuldades não previstas na sala de aula, que foram motivo de grande perturbação para a professora que diz, "Preciso estudar mais e fazer a experiência sożinha".

As professoras aceitaram a tarefa de produzir a "aula expositiva" e apresentá-la ao grupo, mesmo que com algum desconforto. A pergunta que logo 
apareceu: Como devo fazer? É chegar e por na lousa? O quê? Essa tarefa solicitada tinha a intenção de sistematizar/organizar o conteúdo que elas julgavam que havia sido ensinado, e certamente exigia de qualquer professor um bom conhecimento do conteúdo específico, além de trânsito razoável com as concepções prévias dos alunos. Talvez, inconscientemente, essa exigência fosse o motivo da surpresa, do desconforto e da sensação de incapacidade para a tarefa.

Os resultados que encontramos em termos do desempenho das professoras nessa produção, cujos resultados específicos foram analisados em Scarinci e Pacca (2005), nos levaram a explorar a mesma tarefa para outras atividades comuns no ensino. Neste caso consideramos particularmente a "aula de demonstração" e a "aula experimental". Diferentemente da tarefa anterior, essas aulas não precisaram ser solicitadas explicitamente porque já constavam dos planejamentos e pareciam adequadas ao construtivismo desejado, mas constituíram uma oportunidade para serem questionadas quanto ao significado e à propriedade de introduzi-las como atividades dentro de seus planejamentos.

Os resultados a seguir referem-se a essas várias situações, analisadas com base nos materiais de que dispúnhamos e mais alguns depoimentos espontâneos.

\section{ANÁLISE DOS RESULTADOS}

\section{Sobre a concepção de "aula expositiva"}

Em certo momento, quando uma boa parte do conteúdo já havia sido estudada e o desenvolvimento dos planejamentos das professoras já estava adiantado (tendo levado experimentos e atividades em classe, capazes de conduzir os alunos à compreensão da corrente elétrica, da sua condução nos materiais e da sua produção com a pilha eletrolítica), a coordenadora, tendo percebido uma aversão dos professores pela aula expositiva, propôs-se a dar uma aula que contemplasse, naquele momento, o conteúdo essencial, já bastante estudado e esclarecido.

A aula tratou do conteúdo como concebido cientificamente, mas procurou incluir e enfatizar as barreiras conceituais esperadas com as concepções de senso comum, o que pretendia ser uma adesão a um preceito construtivista traduzido para a sala de aula. Foi solicitado que as professoras ouvintes evitassem fazer perguntas e, sempre que possível, anotassem-nas para voltar a elas no final da exposição; isso já foi considerado uma forte restrição no que elas entendiam por construtivismo. Ao final, não apareceram questões sobre o conteúdo e pontos que não estivessem claros ou que pudessem ser tratados de outro modo, mas sim uma reação intensa sobre a própria aula expositiva sendo incluída na programação.

Um comentário imediato: "Professora, a senhora está brincando com a gente!... Porque então tudo que fizemos até agora não tem sentido!" 
Alguns participantes estranharam a ousadia, mas entusiasmaram-se para continuar as críticas. "Como fica o nosso trabalho de discutir tudo com os alunos e partir do conbecimento deles?"

Depois de discutir com o grupo a aula expositiva como atividade planejada, foi proposto pela coordenadora que eles também elaborassem uma aula expositiva para seus alunos e a apresentassem para o grupo. Interessante notar que, a partir desse momento, as dúvidas eram sobre o conteúdo da aula. "É um resumo da matéria?", "É uma síntese?", "Como dar os conceitos numa aula dessas?", "É um fechamento?", "Serve para organizar as ideias?” Ou seja, nesse segundo momento, observamos que a validade de uma atividade aula expositiva não era mais tão preocupante; a dificuldade estava em compreender a natureza da atividade e o que ela comportava.

A coordenadora havia produzido um grande conflito na forma de conceber essa atividade, tão presente nas aulas ditas tradicionais. As professoras, assim, recusavam-se a ser tradicionais, afinal estavam ali para 'serem construtivistas'... e a formadora sugeria uma aula expositiva!

Em algum momento dos planejamentos por cada uma, como sugestão do programa, cada professora planejou uma aula expositiva com a tarefa de trazer os resultados para discussão. Efetivamente, nem todas aplicaram na sala de aula, mas todas tiveram que prepará-la e apresentá-la ao grupo. A aula preparada deveria ser significativa para seus alunos, em um dado momento.

Os resultados da tentativa ou da aplicação com os alunos trouxeram alguma surpresa para as próprias professoras:

\footnotetext{
"Eu ia começar a aula expositiva e não tive coragem; eles não estavam no ponto que eu queria."

"(a aula) não levou em consideração o ponto em que cada aluno está."

"Os alunos pediram que nessa aula eu não fizesse perguntas e falasse o conteúdo."

"Os alunos ficaram em absoluto silêncio e anotando tudo, o que é bastante incomum."
}

A partir daí, as professoras estavam discutindo o que significava uma aula expositiva e sua adequação como uma atividade para a sala de aula. Usaram argumentos vários dando conta de fatores de naturezas diversas: (a) a localização da atividade no planejamento geral, (b) o conteúdo e foco da aula, (c) a aproximação com o conhecimento dos alunos, (d) o rigor dos conceitos científicos e, até mesmo, (e) o que era sugerido como avaliação da aprendizagem.

Esse processo final de conscientização do professor parece ter levado a uma ressignificação da aula expositiva. No momento em que ela precisa ter sentido para a aprendizagem e ser composta com os critérios contidos naqueles argumentos, ela passa a ser caracterizada objetivamente para dar conta da aprendizagem significativa dos conteúdos.

Quanto ao percurso seguido pelos participantes para a ressignificação, identificamos uma fase inicial de estranhamento, que, pela condução da formado- 
ra, logo se transformou em uma problematização, trazendo, adjacentes às concepções dos professores sobre o construtivismo, várias questões muito pertinentes de natureza essencialmente teórica.

Em seguida, houve uma segunda fase, de operacionalização da proposta, que proporcionou uma nova vivência para a aula expositiva e originou questões principalmente de natureza prática e metodológica.

$\mathrm{Na}$ terceira fase, de conscientização do professor e em posse dos resultados de sala de aula, ele conseguiu fazer uma síntese das questões levantadas nas fases anteriores, relacionando a teoria do construtivismo com a prática levada para a sala de aula, no que dizia respeito àquela estratégia em particular.

\section{SOBRE A CONCEPC̣̃̃O DE “AULA DE DEMONSTRAC̣ÃO”}

As ideias das professoras sobre a aula de demonstração entraram em pauta a partir de uma situação vivida por elas no próprio grupo de formação.

No Programa, as professoras dispõem de material para realizarem experiências individualmente, mas sempre com a colaboração ou interferência de todos para resolver os problemas que se apresentam. A formadora geralmente intervém no final de algum trabalho para organizar os resultados e (re)construir o conteúdo conceitual. Essa atuação da formadora pode ser exemplificada com o seguinte acontecimento:

Figura 1: espaço sem limalha em região próxima ao ímã

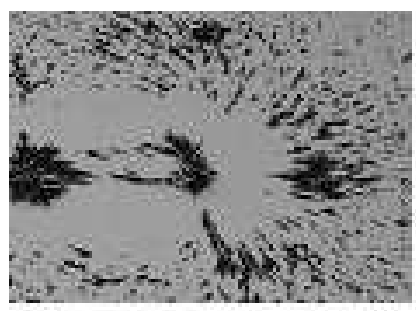

Num experimento em que se visualizava o campo magnético, espalhando limalha sobre o papel que recobria um ímã em forma de barra, a configuração encontrada deixava um espaço vazio (em branco no papel) na região mais próxima do ímã (Figura 1). A formadora percebeu que uma professora procurava, com um pincelzinho, ocupar esse espaço com limalha (o que era certamente impossível); diante dessa situação, propôs um problema ao grupo: Por que fica um espaço vazio? É possivel calcular (estimar) a intensidade do campo magnético num ponto situado no limite dessa linha, dessa região?

Depois de analisarem a situação, pareceu boa a ideia de atribuir ao atrito da limalha com o papel a existência do espaço vazio. Como então medir a 
força de atrito nesse caso, para associá-la à força magnética de igual intensidade? Uma professora (PLA) lembrou-se de um procedimento da Mecânica, utilizando um plano inclinado cujo ângulo pudesse ser variado; montou o experimento e mostrou aos demais como calcular.

Chegando a esse ponto, ficou como tarefa para casa repetirem a experiência e tomarem medidas para o cálculo do campo magnético naquele ponto, a partir da determinação da intensidade da força de atrito. Poucas conseguiram e outras apresentaram dúvidas quanto ao problema em questão: como se havia chegado à necessidade de calcular a força de atrito.

Essa dificuldade trouxe consigo uma evidência de que a discussão conduzida pela formadora levara a procedimentos experimentais não acompanhados por todas as professoras. Quando a aula assumiu características de demonstração, isto é, quando PLA, que resolvera o problema, mostrou a resolução aos outros participantes, houve um distanciamento destes da possibilidade de compreensão do fenômeno. A percepção desse distanciamento aparece na expressão de uma professora:

\footnotetext{
"Mas é interessante, se a gente pegar a nossa aula prática do ímã, da limalha de ferro e tal... Veja só, nós fizemos a experiência... depois nós conversamos por que ficava a limalha naquele ponto e tal..., você vê que aí foi uma discussão, né? Foi uma aula experimental. Mas pra gente chegar no cálculo da força de atrito... quer dizer..."
}

Um conflito parece ter se instalado com a frustração das professoras. A dificuldade parecia não se limitar à medida da força de atrito (o que já consistia uma novidade), mas estender-se à sequência e ao encadeamento do problema que trouxe como proposta uma medida da força magnética - e essa sequência fora acompanhada numa demonstração que somente algumas puderam compreender.

Esse conflito contextualizou a investigação do que ocorre com uma aula de demonstração e de como as professoras entendiam essa atividade. A formadora perguntou diretamente a elas - O que é uma aula de demonstração? Qual sua função numa sequência de ensino?

De modo geral, para todas parecia que nada do que fora feito tinha característica de uma aula de demonstração, mas, inegavelmente, todos os procedimentos eram considerados construtivistas.

Sobre a pergunta específica, as respostas se referiam especialmente ao papel funcional e pragmático da aula de demonstração: para demonstrar a teoria, para resolver o problema da falta de material para todos, para motivar um certo tema de estudo, para manipulação do professor que quer mostrar um efeito visível para todos, para lidar com conteúdos experimentais.

Uma professora mostrava uma compreensão que ligava a aula de demonstração a uma dedução matemática que era desenvolvida na lousa e usou o termo 'aula demonstrativa'. Essa ideia, mesmo sendo surpreendente para nós, 
trouxe dúvidas para o grupo. Outras ainda tratavam a atividade com o ímã como uma aula experimental. Os resultados sobre as concepções de aula de demonstração, em detalhe, foram relatados em Scarinci \& Pacca (2006). Aqui, enfatizaremos principalmente a função dessa atividade na concepção das professoras.

A questão focalizada foi a inclusão de uma aula de demonstração no planejamento real. Para as professoras, não se punha em dúvida o caráter construtivista porque, afinal, "era uma situação experimental", mas a questão primordial foi em que ponto do planejamento colocá-la. Os exemplos a seguir trazem grifos das autoras para apontar a informação significativa para a análise efetuada.

“[aula é de demonstração] ${ }^{1}$ quando o aluno, por exemplo, já fez essa parte [na aula teórical, e aí você quer que ele perceba quais os conceitos que estão envolvidos ali... Aí com a experiência, no caso, o professor faz lá na frente; o aluno, é que nem você falou, já tem algum conhecimento."

"A demonstração, o professor faz, os alunos olham, observam, pode ser um momento de chegar ao assunto logo."

Como a localização no planejamento foi conectada aos objetivos de forma implícita, a discussão foi então encaminhada buscando-se aprofundar o conhecimento e o significado dessa atividade, com a questão - Como se pode caracterizar o objetivo para o qual a aula de demonstração seria adequada?

"A gente pode estar dizendo o que ele observar a respeito, para que ele possa pensar sobre o... porquê de aquilo estar acontecendo."

"Dependendo da experiência que você vai fazer é tão complexo e eles se perdem tanto [se eles mesmos fizerem o experimento] que acaba perdendo o objetivo que você tinha no começo, então era melhor você fazer e mostrar. Não todas..."

Nessa frase, com alguma dúvida, a professora procura um objetivo para a aula de demonstração e parece querer salvar o caráter construtivista com a expressão "você fazer e mostrar... não todas..."

"[Fui] procurar no dicionário o que é demonstração - que é você mostrar, o aluno não tá mexendo no material, não é ele que está fazendo, o professor tá fazendo, tá mostrando."

"Porque é muito diferente a gente [como aluno] fazer a experiência, poder discutir depois, ver as dificuldades, né? Porque isso conta muito."

A aula de demonstração estava sendo comparada com a aula experimental, de forma mais implícita nos depoimentos anteriores e mais explícita neste último, em que a professora declara que a manipulação do material pelo aluno seria mais adequada que apenas a observação. As professoras procuraram justificar a adoção de uma atividade de demonstração em condições em que a ati- 
vidade experimental está impossibilitada: experimento complexo, falta de material para todos, falta de tempo. A função de uma aula de demonstração seria, então, a mesma de uma aula experimental.

A ressignificação da aula de demonstração pareceu começar a ocorrer quando se voltou à análise do que aconteceu durante a experiência com o ímã e se localizou em que momento desse desenvolvimento ela passou a ser uma demonstração, que dificuldades apareceram e por quê. A função da demonstração pôde ser então pensada e adequada aos objetivos.

A aula de demonstração tem a exigência de que todos possam acompanhá-la e compreender o encadeamento de ideias que justificam os procedimentos realizados pelo sujeito que está realizando o experimento. Assim como esse acompanhamento se perdeu na experiência com o ímã, também poderia acontecer em sala de aula, quando a expectativa do professor sobre a compreensão dos alunos não está, de todo, realizada.

Assim, a reelaboração das ideias das professoras requereu a análise de que a demonstração exige um certo conteúdo estabelecido para favorecer uma comunicação com os alunos e avançar para um novo conhecimento ou gerar novas questões.

Identificamos, também, fases no desenvolvimento dos professores sobre essa estratégia de ensino. $\mathrm{Na}$ fase que poderíamos chamar de preliminar, ocorreu uma vivência de aula de demonstração em que um dos participantes fez o papel de professor-demonstrador e outros o papel de alunos. Alguns acompanharam o raciocínio e os procedimentos do demonstrador, outros se perderam no caminho. Iidentificamos a situação como um estranhamento.

A formadora usou o incômodo gerado para problematizar a estratégia, que marcou o início de outra fase, de operacionalização, em que as professoras tentavam caracterizar a ação, mas ainda sem conectá-la à sua prática docente ou à experiência vivida na fase anterior. Novamente, surgiram questões das professoras sobre o construtivismo, embutidas nas suas explorações e explicações sobre o uso dessa estratégia.

A terceira fase, de conscientização, ocorreu a partir do momento em que houve uma conexão com a prática e identificação da experiência vivida (do ímã e limalha) como uma atividade de demonstração. A partir disso, outras atividades realizadas em sala de aula e constantes dos planejamentos dos professores puderam ser identificadas como demonstrações.

\section{SOBRE A CONCEPCฺ̃̃O DE "AULA EXPERIMENTAL"}

Ao mesmo tempo em que se referiam à aula de demonstração, a aula experimental aparecia nos discursos e, esta sim, parecia mais clara e definida quanto aos objetivos e enquadrava-se bastante bem como uma atividade construtivista. 
"Aquele dia que eu montei, que eu fui fazer a ligação em série e montei o circuito, que eles não enxergavam o que estava acontecendo, eles não gostaram da aula. Daí com aquele material que eu levei, nossa(!) foi uma boa aula, eu dividi em grupos, eles fizeram, ficaram contentes, queriam abrir, queriam ver, então é diferente."

A aula experimental é, sem dúvida, concebida como construtivista e a mais adequada para ensinar e aprender, mesmo que as razões para isso sejam duvidosas ou até inconscientes. Mas, na frase acima, a sensação de satisfação experimentada pela professora e alunos parece indicar que o procedimento foi adequado.

A caracterização necessária para a aula experimental que a diferencia da de demonstração é que a atividade individual dos alunos com a manipulação permite organizar ideias, experimentar hipóteses, escolher e seguir seu próprio ritmo na caracterização do fenômeno. Essa conceituação deve ser capaz de fornecer os critérios para entender os usos das duas estratégias.

Toda aula que inclui alguma manipulação empírica era considerada como aula experimental. As professoras não diferenciavam o papel do experimentador estando representado pelos alunos ou pelo professor e as consequências educativas dessa escolha. Eles admitiam, no entanto, que a "aula experimental" em que somente o professor manipula os materiais requer envolvimento menos ativo dos alunos.

Numa tentativa de salvar uma aula de demonstração dentro de uma conceituação construtivista, a professora usa de um recurso interessante: "A demonstração, nunca deve o professor fazer a experiência, sempre deve orientar um aluno e ele [o aluno] fazer."

Isto quer dizer que, quando não é possível ter material para todos, pelo menos que seja convidado um aluno para manipular, talvez porque a interação pudesse ser mais significativa para os alunos estabelecendo-se uma ponte entre eles e a professora.

Referindo-se a uma aula experimental em que o resultado não havia sido encontrado por falta de condições experimentais adequadas ou por falta de tempo para corrigir defeitos da montagem, uma professora resolveu que, na aula seguinte, faria o experimento como uma demonstração para chegar ao resultado esperado, por ela e pelos alunos:

\footnotetext{
"Na experiência da montagem da pilha, eles queriam ver a lâmpada acender e o motorzinho funcionar, queriam o resultado e não houve tempo ... eles ficaram ansiosos porque não acendeu ... $\mathrm{Na}$ aula seguinte cheguei mais cedo e fiz essa aula - de demonstração na realidade - né, encaixa bem nesse termo [conceito] de demonstração - e quando surgiu o efeito da experiência, fazer o motorzinho funcionar, eles aplaudiram (!) ... Depois a gente discutiu, por que não acendeu antes, por que acendeu agora. ... Dei o fechamento da aula... Eu acho que essa aula de demonstração foi uma experiência que eu tive esse ano que deu certo."

“(Depende de) até que ponto o professor consegue aguçar aquela curiosidade dele... que é um querer do aluno."
} 
Nesse caso, a professora, ao relatar e justificar as aulas que dera, conseguiu caracterizar os dois momentos distintos associados a atividades diferentes quanto ao processo de aprendizado (percebemos que a nomeação para as atividades experimental e de demonstração foi dada durante o relato). A demonstração foi feita no momento em que os alunos já haviam experimentado a situação mesmo sem chegar ao resultado esperado. De qualquer modo, a aula experimental era fundamental para que a demonstração posterior tivesse sentido.

No caso da aula experimental como concebida pelas professoras, a primeira e a segunda fase não apareceram enfaticamente. Parece que essa atividade faz um sentido correto se pensado com o construtivismo concebido.

Durante o processo de ressignificação das atividades, a professora conseguiu conceber o construtivismo de uma nova forma, percebendo a participação ativa dos alunos que atividades de demonstração podem permitir, mesmo sem uma manipulação ou interação direta com o material, desde que estejam presentes certas condições de conhecimento prévio e de envolvimento com um problema. Essa conscientização lhe permitiu também maior suporte teórico para a própria atividade experimental.

Com o desenrolar dessa sequência de trabalho para uma tomada de consciência da função da atividade em questão, as discussões haviam produzido um problema que era de todas e que exigia uma reflexão sobre o processo que havia sido experimentado por cada uma.

A consciência do papel de cada participante diante da 'demonstração' e da função da tarefa parece ter levado à ressignificação de ambas as estratégias de ensino (a demonstração e a aula experimental). Conforme o significado da aula de demonstração ficava claro, com respeito à atividade do aluno que assiste (observa) e do professor que mostra (demonstra), a aula experimental pôde ser revista e recaracterizada por comparação. A significação da aula de demonstração permitiu uma ressignificação quanto às características que a diferenciam da aula experimental: "[A aula de demonstração] tem a ideia de aula expositiva porque é uma pessoa controlando de certa forma o conbecimento, o assunto que você quer passar. Que nem aula expositiva na lousa, ... que é uma pessoa que controla aquilo que tá falando ..."

A fase de operacionalização ocorreu quando as professoras foram requeridas a diferenciar a aula experimental da aula de demonstração. Como a aula experimental parecia estar clara para elas, o problema concentrou-se em saber do que tratava a aula de demonstração e em que essa se diferia da experimental. Para isso, recorreram a atividades realizadas com seus alunos e realizadas por elas como alunas e ensaiaram classificá-las como experimental ou de demonstração. $\mathrm{Na}$ fase final, de conscientização, as professoras foram capazes de chegar a essa comparação entre as atividades, porém sem chegar a uma caracterização final e completa da aula experimental.

Quanto ao percurso seguido pelas professoras na ressignificação de cada uma das atividades, percebemos a necessidade que tiveram de responder a questões de ordem teórica, mas também de recorrer continuamente às suas 
vivências das atividades, tanto na condição de alunas como de professoras. A ressignificação ocorreu quando foram encontradas respostas coerentes tanto em nível teórico quanto metodológico e prático, e quando a professora conseguiu estabelecer claramente diretrizes para sua atuação em sala de aula correspondentes ao recente aprendizado.

\section{CONCLUSÕES:}

\section{AS CONCEPC̣ÕES PRÉVIAS SÃO PASSÍVEIS DE MUDANC̣A}

Que é "ressignificar uma atividade"? A falta de reflexão sistemática sobre estratégias usuais de aula faz com que permaneçam as concepções ingênuas e o construtivismo fica relegado ao mundo das ideias. A chamada para dar significado a essas estratégias, em coerência com a nova concepção de ensino e aprendizagem adotada, levou ao próprio aprofundamento da teoria construtivista na sala de aula e do que ela significa em termos dos papéis assumidos por alunos e professor. A teoria pôde ser operacionalizada.

Macedo (1994) aponta para essa questão da ressignificação das atividades escolares como forma de aproximar o ensino na sala de aula do construtivismo piagetiano. Ressignificar aparece aqui dependente de diversos elementos que caracterizam uma aula real e cotidiana. Alguns podem ser citados de imediato, por se relacionarem diretamente aos resultados da nossa análise.

0 envolvimento do sujeito na situação. As atividades serão significativas se capazes de levar ao envolvimento profícuo dos aprendizes. Para o construtivismo, a ação observável deve ser espontânea ou produto de algo que apenas a desencadeia, sem nunca induzi-la. Esta sutileza é confundida com obter respostas sem uma garantia ou indício de que ela representa um pensamento autêntico do aluno e derivado de uma teoria própria, mesmo que distante da científica.

0 conflito cognitivo para ensinar a "teoria correta". As atividades capazes de proporcionar uma mudança conceitual efetiva precisam colocar em xeque o pensamento atual do sujeito. Aquilo que parece uma situação de contradição para o professor nem sempre constitui um conflito para a concepção do aluno, porque não põe em xeque a teoria alternativa que suporta aquela resposta errônea. $\mathrm{O}$ confronto no diálogo das ideias suposto pelo professor não ocorre de fato, o que parece existir é uma disputa entre dois monólogos.

0 respeito às ideias prévias. Partir das ideias prévias para construir o conhecimento adequado, respeitando concepções construtivistas, não pode ser confundido com uma impossibilidade de avanço na direção de uma reconstrução. Isto certamente demanda uma intervenção do professor para a orientação do caminho que leva às concepções científicas. Muitos professores têm se conformado em parar num certo nível insuficiente de conteúdo, esperando que o aluno chegue sozinho ao conhecimento que foi socialmente estabelecido. De fato isto não vai acontecer tão facilmente; e no próprio construtivismo é aceita 
a ideia de que o meio deve oferecer desafios, graças aos quais as teorias alternativas são reestruturadas.

Estes parecem ser os pontos mais evidentes nas dificuldades que os professores enfrentam para planejar suas atividades e conduzi-las adequadamente. Assim, as aulas expositivas não têm lugar no planejamento, as aulas de demonstração são úteis para mostrar o que os alunos devem saber, as aulas experimentais são sempre as mais adequadas e devem estar presentes todo o tempo. Com isto, está fora de cogitação admitir momentos planejados onde o sujeito pode pensar suas próprias ideias, fazer sínteses, ouvir e refletir sobre o que ouve. Isto é, constitui-se, sem perceber, uma situação de ensino transmissivo com outra roupagem: a aula expositiva não é capaz de organizar o pensamento e prepará-lo para avançar; a aula de demonstração é uma aula de show que diverte, mas não ensina; a aula experimental disponibiliza o material, mas leva receitas para serem seguidas. Todas as situações colocam o aprendiz passivo e não agente da sua aprendizagem.

As atividades didáticas, numa outra situação em que está em jogo o protagonismo do sujeito que aprende, serão basicamente sempre as mesmas, o que deve mudar é a condução das aulas e, para isso, o professor deve ressignificar as atividades que apresenta aos seus alunos, definindo melhor os objetivos e o trabalho dos alunos de forma coerente com o construtivismo em que nos baseamos aqui. Essa condução implica em ouvir o aluno, procurando compreender o que está por trás das respostas errôneas e aí, então, estabelecer os conflitos cognitivos autênticos e significativos para a situação ao mesmo tempo em que novos desafios devem continuar na direção do novo conhecimento a ser alcançado.

Não são as atividades as responsáveis por um ensinar construtivista ou não construtivista, mas a maneira como elas são entendidas e consideradas na sala de aula. Ou seja, o construtivismo não está exatamente na atividade que o professor apresenta, mas na maneira como ocorre a interação entre professor e aluno com interesses em resolver os problemas que têm significado para ambos e no enfrentamento das dificuldades ao assumir uma linguagem que busca aproximar professor e aluno num diálogo de fato. 


\section{NOTA}

1 Colchetes indicam resumo de uma fala, ou uma expressão que auxilia o leitor a compreender o contexto em que o depoimento está inserido.

\section{REFERÊNCIAS BIBLIOGRÁFICAS}

FREIRE, P. Pedagogia da Autonomia: saberes necessários à prática educativa. São Paulo: Paz e Terra, 1996.

FUSARI, J.C. Em defesa de uma política de formação contínua de educadores. Educação em Debate (CESA/UFC), São Paulo, n. 1, p. 64-66, 1998.

LAJONQUIÈRE, L. de. Acerca da instrumentação prática do construtivismo: a (anti)Pedagogia piagetiana, Ciência ou Arte? Cad. Pesq. São Paulo, n. 81, p. 61-66, 1992.

MACEDO, L. Ensaios Construtivistas. São Paulo: Casa do Psicólogo, 1994.

PACCA, J. \& VILLANI, A. La competencia dialógica del profesor de ciencias en Brasil. Enseñanza de las Ciencias, Ourense(Spain), v18 n(1), p 95-104, 2000.

PIAGET, J. O desenvolvimento do pensamento: equilibração das estruturas cognitivas. Lisboa: Dom Quixote, 1977.

SCARINCI, A. \& PACCA, J. L. A. Construtivismo na sala de aula: concepção dos professores sobre a função da aula expositiva. In: ENCONTRO NACIONAL DE PESQUISA EM EDUCAÇÃO EM CIÊNCIAS, 5., 2005, Bauru, SP. Atas do V ENPEC, Bauru: ENPEC, 2005.

SCARINCI, A. L. \& PACCA, J. L. A. Concepções dos professores sobre a aula de demonstração. In: ENCONTRO DE PESQUISA EM ENSINO DE FÍSICA, 10., 2006, Londrina, PR. Atas do $X$ EPEF, Londrina: EPEF, 2006.

VILLANI, A. \& PACCA, J. L. A. Un curso de actualización y cambios conceptuales en profesores de Física. Enseñanz̧a de las Ciencias, Ourense(Spain) v. 14, n. 1, pp. 25-33, 1996.

VILLANI, A. \& PACCA, J. L. A. Estratégia de ensino e mudança conceitual na atualização de professores. Rev. Bras. Ens. de Fís., Porto Alegre, v. 14, n. 4, pp. 222-228, 1992. 